\title{
Venereal Diseases in Mexico
}

\author{
ANTONIO CAMPOS SALAS, M.D., M.P.H.
}

$\mathbf{N}_{\mathrm{t} \text { tiva }}^{\mathrm{o}}$ OTEWORTHY PROGRESS in the control of venereal diseases in Mexico is indicated by the extensive data collected by the Mexican Ministry of Public Health. The mortality and morbidity rates of syphilis and gonorrhea show a steady decline (tables 1 and 2 ).

This decline, considered by itself, has given rise to the belief among some public health workers and members of the medical profession that syphilis and other venereal diseases have been or will be defeated soon simply by the passage of time and the application of present treatment. These optimists do not take into account the factors which cause the decline in the rates to appear greater than it really is.

Unjustified optimism is detrimental to progress in control. It encourages a leveling off and even a drop in effort which will result in a future increase in the incidence of the diseases. Although the incidence of venereal diseases has abated in some parts of Mexico, these diseases still constitute a public health menace in some communities.

Fortunately, the recent establishment and improvement of well-staffed and well-equipped

- health centers should contribute to the reduction of venereal diseases.

Death notifications submitted by private physicians constitute a major part of the Ministry's data on mortality. In some cases the physicians consider it in the interest of their patients' families to change the cause of death from syphilis to some other cause. This means that

Dr. Campos Salas is chief, National Campaign Against Venereal Diseases, Ministry of Public Health, Mexico. This article is based on a paper given at the United States-Mexico Border Public Health Association meeting in San Diego, Calif., June 26, 1961. the real syphilis mortality rates are not as low as the registered ones. But since this practice by private physicians has prevailed consistently over the years, the indicated decline in syphilis mortality is a real one (table 1 ).

Among the 10 leading transmissible diseases reported to the Ministry of Health during 1960, syphilis occupies fifth place, and gonorrhea, eighth. If account is taken of the fact that physicians omit reporting of venereal disease cases to a greater degree than other transmissible diseases, it is possible that these two diseases may rank even higher.

The statistical data available on venereal diseases are obtained largely from the field services of the Ministry of Health, located in communities where approximately 55 percent of the total population resides. Although these statistics come from the same source, are less subject to adventitious factors, and are considered to be the most adequate for comparison, they do not reflect the true incidence of these diseases even in the communities represented, since the field services are not used by all the inhabitants.

\section{Syphilis}

Table 2, which refers to reported morbidity of syphilis and gonorrhea during the years 1943 to 1960 , shows a significant decrease in the rate per 100,000 inhabitants for both diseases. The decline has been much slower during the past 10 years than in previous years. This may perhaps be explained by the increasing intensification of case investigation.

Figure 1 shows cases of acquired and congenital syphilis registered in the years 1956-60. The congenital group consists mainly of late cases. 
Figure 2 shows the trend observed in primary and secondary syphilis. There is a marked progressive decline in the volume of cases reported during the years 1950-60. The rate per 100,000 inhabitants dropped from 24.2 in 1950 to 5.3 in 1960 . This decrease in the incidence of primary and secondary syphilis requires careful study to determine its true significance. It may mean fewer cases occurring in the communities or decreased knowledge of their occurrence. Knowledge of the cases is directly influenced by the spontaneousness of the patients in reporting to the services and by the activities of the services in discovering patients who do not come on their own initiative. Investigations in some communities indicate that a significant proportion of the patients recently infected with syphilis or gonorrhea, especially the latter, do not go to physicians but resort to self-medication, to remedies sold in drugstores, or to other methods. This situation has been influenced undoubtedly by the progressive reduction in the price of penicillin, knowledge among the people of the effectiveness of penicillin in syphilis and gonorrhea, and lessened fear of these diseases. The discovery of recently infected persons and investigation of contacts cannot be considered satisfactory as yet in various regions of the country.

The relationship between primary and secondary cases of syphilis and early latent cases

Table 1. Reported syphilis mortality in Mexico, 1950-5.8

\begin{tabular}{|c|c|c|c|c|}
\hline \multirow[b]{2}{*}{ Year } & \multicolumn{2}{|c|}{$\begin{array}{l}\text { General } \\
\text { mortality }\end{array}$} & \multicolumn{2}{|c|}{$\begin{array}{l}\text { Infant mortality } \\
\text { (less than } 1 \text { year) }\end{array}$} \\
\hline & Deaths & $\begin{array}{c}\text { Rate } \\
\text { per } \\
100,000 \\
\text { popula- } \\
\text { tion }\end{array}$ & Deaths & $\begin{array}{c}\text { Rate } \\
\text { per } \\
10,000 \\
\text { live } \\
\text { births }\end{array}$ \\
\hline $\begin{array}{l}1950 \\
1951 \\
1952 \\
1953 \\
1954 \\
1955 \\
1956 \\
1957 \\
1958\end{array}$ & $\begin{array}{r}1,897 \\
1,624 \\
1,516 \\
1,381 \\
1,176 \\
1,119 \\
1,087 \\
840 \\
805\end{array}$ & $\begin{array}{l}6.5 \\
5.5 \\
5.0 \\
4.5 \\
\text { 3. } 7 \\
\text { 3. } 5 \\
3.4 \\
2.6 \\
2.4\end{array}$ & $\begin{array}{l}969 \\
815 \\
707 \\
652 \\
559 \\
490 \\
462 \\
342 \\
277\end{array}$ & $\begin{array}{r}\text { 10. } 8 \\
9.1 \\
7.9 \\
\text { 7. } 2 \\
6.2 \\
\text { 5. } 4 \\
4.6 \\
3.4 \\
2.8\end{array}$ \\
\hline
\end{tabular}

Source: Secretary of Health and Assistance, Division of Biometry and Biostatistics.
Table 2. Syphilis and gonorrhea morbidity in Mexico, 1943-60

\begin{tabular}{|c|c|c|c|c|}
\hline \multirow{2}{*}{ Year } & \multicolumn{2}{|c|}{ Syphilis } & \multicolumn{2}{|c|}{ Gonorrhea } \\
\hline & Cases & $\begin{array}{c}\text { Rate per } \\
100,000 \\
\text { popula- } \\
\text { tion }\end{array}$ & Cases & $\begin{array}{c}\text { Rate per } \\
100,000 \\
\text { popula- } \\
\text { tion }\end{array}$ \\
\hline $\begin{array}{l}1943 \\
1944 \\
1945 \\
1946 \\
1947 \\
1948 \\
1949 \\
1950 \\
1951 \\
1952 \\
1953 \\
1954 \\
1955 \\
1956 \\
1957 \\
1958 \\
1959 \\
1960\end{array}$ & $\begin{array}{l}46,187 \\
44,434 \\
40,607 \\
39,919 \\
39,844 \\
32,622 \\
31,694 \\
29,178 \\
24,117 \\
22,924 \\
22,391 \\
23,115 \\
23,982 \\
25,005 \\
24,955 \\
22,429 \\
22,397 \\
23,817\end{array}$ & $\begin{array}{r}223.0 \\
211.3 \\
190.5 \\
184.4 \\
181.3 \\
146.3 \\
140.2 \\
113.1 \\
90.9 \\
83.6 \\
79.8 \\
80.1 \\
80.8 \\
82.0 \\
79.7 \\
69.8 \\
67.8 \\
68.8\end{array}$ & $\begin{array}{l}33,876 \\
28,564 \\
27,813 \\
27,500 \\
27,157 \\
26,314 \\
25,456 \\
23,000 \\
23,188 \\
23,515 \\
23,104 \\
23,323 \\
21,309 \\
19,782 \\
17,778 \\
19,129 \\
20,364 \\
19,105\end{array}$ & $\begin{array}{r}158.1 \\
129.9 \\
123.1 \\
118.6 \\
114.0 \\
107.5 \\
101.2 \\
89.2 \\
87.4 \\
86.7 \\
82.3 \\
80.8 \\
71.8 \\
64.8 \\
56.7 \\
59.5 \\
61.6 \\
55.2\end{array}$ \\
\hline
\end{tabular}

Source: Secretary of Health and Assistance, Division of Epidemiology and Sanitary Campaigns, National Campaign Against Venereal Diseases.

also leads to reservations regarding the drop registered in primary and secondary syphilis cases. If patients are discovered and treated effectively during the period of primary or secondary syphilis, they do not become early latent cases. Accordingly, the increase in the proportion of these latent cases to recent symptomatic cases logically signifies that the ailment was not recognized during its initial phases, or that it did not receive adequate treatment. The average ratio of recent symptomatic syphilis cases to early latent cases was 1 to 1.1 during the years 1950 through 1952, and 1 to 2.7 from 1958 through 1960.

Figure 3 shows the number of primary and secondary, early latent, and late latent cases, by sex. Each year, from 1958 through 1960, fewer women than men were discovered in the recent symptomatic phase, but this relationship between sexes was inverted in the early latent cases. Since the serologic investigations in the country are balanced so far as sex is concerned, it may be deduced that numerous cases of recent symptomatic syphilis in women go undiagnosed. For the control of syphilis, it is 
necessary to discover these cases. During the 3 years covered in this chart, the reported number of recently infected women was less than half that of the men. Two principal factors may explain this: (a) numerous primary lesions, which are generally located on the genital organs, are unnoticed in women because of the morphology of their reproductive organs and $(b)$ women are less willing than men to attend the field services of the Ministry or, possibly, any other source of treatment.

Figure 1. Number of cases acquired and congenital syphilis in Mexico, 1956-60

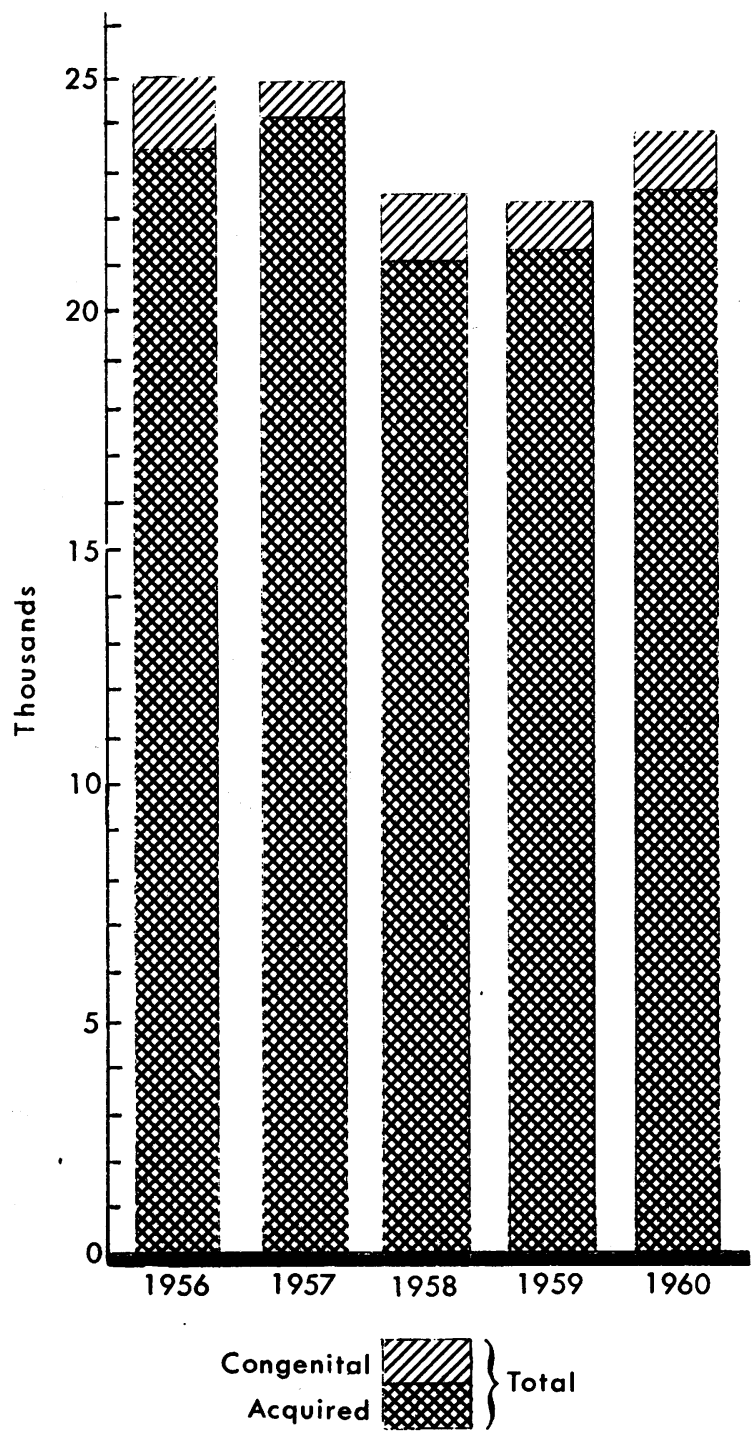

Source: Secretary of Health and Assistance, Division of Epidemiology and Sanitary Campaigns, National Campaign Against Venereal Diseases.
Figure 2. Syphilis in Mexico, 1950-60

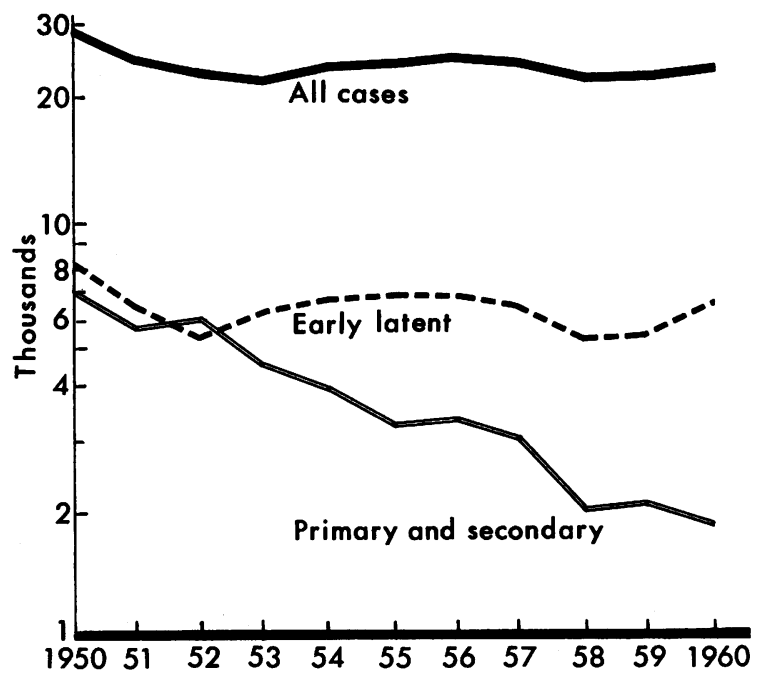

Source: Field Services report of the Secretary to the Division of Epidemiology and Sanitary Campaigns, National Campaign Against Venereal Diseases.

The results of serologic investigations carried out in 1960 support the affirmation that reported morbidity represents only a part of that which exists (1). These results show not only high percentages of seropositivity in certain socioeconomic groups of the population but also that many of these persons were unaware of the condition, either because they had never been the object of serologic study or because in the last study made they were sero-negative.

\section{Gonorrhea}

The true incidence of gonorrhea is even more difficult to determine than that of syphilis, especially in women, because of the not very satisfactory methods of diagnosis. The index of gonorrhea in men is considered to be a good indicator of the trend in incidence. The rate per 100,000 male inhabitants declined progressively from 100.6 in 1950 to 54.8 in 1960. For a correct evaluation of this decline, however, it should be remembered that the data obtained in special investigations show that the majority of recently infected patients resorting to selfmedication or drugstore treatment are men who suffer various types of urethritis, among them gonorrhea. In any case, the clinical evolution of this disease has not changed, either with respect to its transmissibility or to the belated 
complications it produces. We do not have sufficient statistical data regarding the number of these complications to clearly support a decline.

Important advances in the control of venereal diseases in Mexico are manifested in the declining trend of both general and infant mortality in syphilis, the declining trend in the rates of reported syphilis morbidity, and in the incidence of primary and secondary syphili.s and of gonorrhea.

Nevertheless, venereal diseases continue to constitute an important public health problem, since the fundamental reason for the control of these transmissible diseases is not to inhibit transmission but to prevent the incapacitation and death they can cause. Even though we were to assume that all the recently infected patients unknown to us receive treatment outside medical control, there is no assurance that they have been really cured and the possibility of complications removed. There is even less certainty that they have not spread their infection, exposing other persons to possible incapacitation and death.

As long as the number of early latent syphilis cases remains disproportionate to that of primary and secondary cases, as long as late latent syphilis rates remains higher than those of early latent cases, as long as we continue to discover by serologic investigation numerous persons who have not received treatment be-

Figure 3. Primary and secondary, early latent, and late latent cases of syphilis, by sex, Mexico, 1958-60

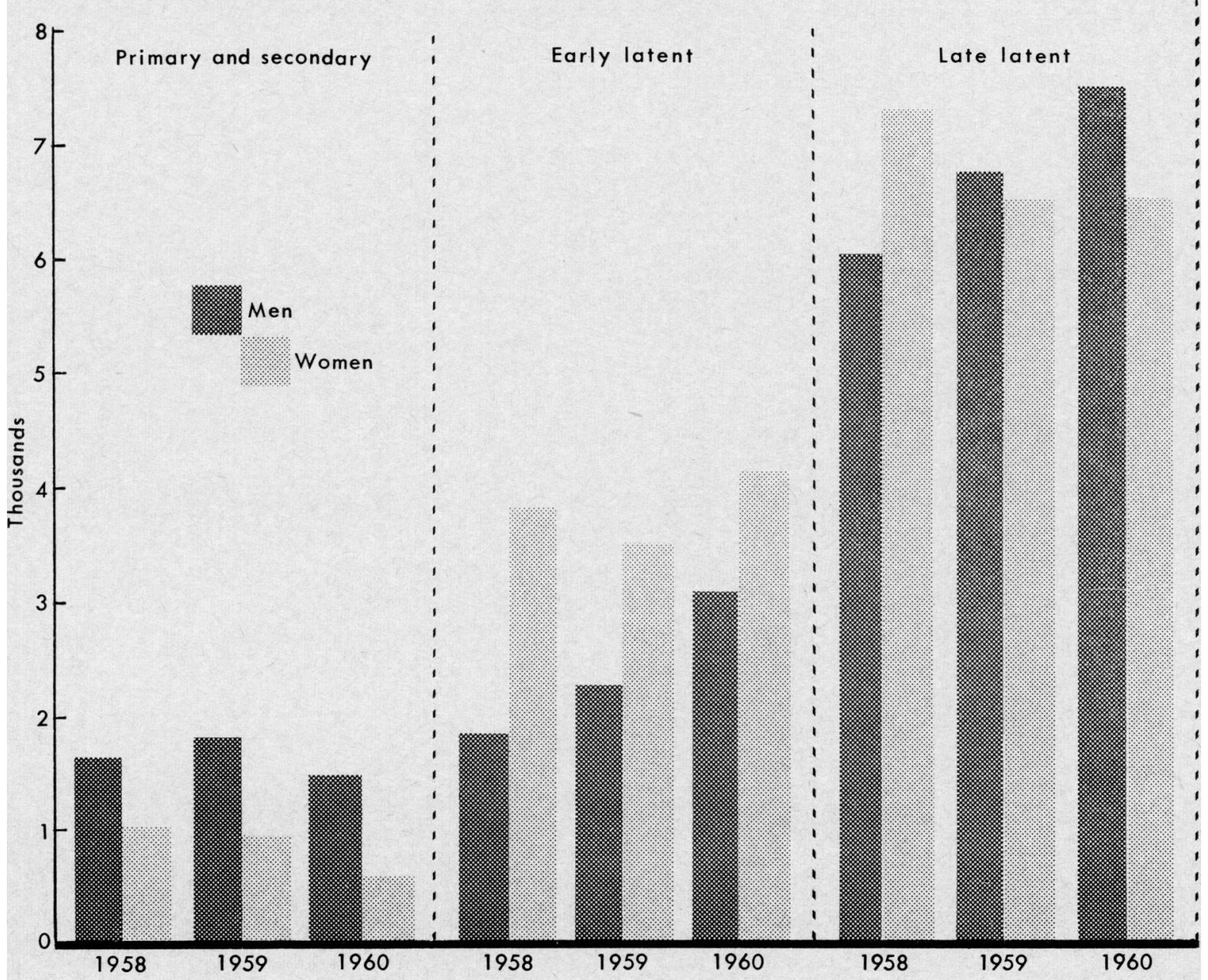

Source : Field Services report of the Secretary to the Division of Epidemiology and Sanitary Campaigns, National Campaign Against Venereal Diseases. 
cause they are unaware of their pathological state, we cannot but admit that venereal diseases continue to constitute a serious public health threat in Mexico.

\section{Conclusions}

Control activities attempt to reduce the number of persons who acquire venereal diseases, to find and treat recent cases in order to prevent dissemination, and to discover and treat all cases of syphilis in order to prevent, or at least detain, the grave or mortal complications.

To achieve these aims, we must gather more information in order to better appreciate the location and magnitude of the local problems and improve the discovery of cases by amplifying a selective program of antivenereal disease information, by extending serologic examinations in localities of the greatest known or suspected incidence, and by intensifying the investigation of contacts.

We consider it indispensable to continue our efforts to bring up to date the antivenereal dis- ease information among the medical profession and to improve the training of public health personnel, in particular the contact investigators.

We believe it wise to center attention on the principal geographic foci of syphilis and gonorrhea, emphasizing syphilis first, gonorrhea next, and finally the other venereal diseases.

All this requires the use of more materials, not only to maintain existing facilities for diagnosis and treatment but also to intensify these activities, to increase efforts to identify and reduce the high resistance foci, and to meet the magnitude and complexity of the venereal disease problem.

\section{REFERENCE}

(1) Campos Salas, A., Verduzco Peñafiel, A., and Montaño Vallejo, V.: Sífilis. Algunos aspectos de su epidemiología en México. Boletín Epidemiológico; Secretaria de Salubridad y Asistencia 25 : abril, mayo y junio 1961.

\section{New Home for National Library of Medicine}

The new quarters of the National Library of Medicine on the grounds of the National Institutes of Health in Bethesda, Md., will house the world's greatest collection of medical literature. The $\$ 7$ million structure, designed by the firm of O'Connor \& Kilham of New York City, has space for about 11/4 million bound volumes on its five floors, three below ground. The library's collections at 7th and Independence, SW., Washington, D.C., and its historical and rare book collections, now in Cleveland, Ohio, will be transferred to Bethesda in the spring of 1962. The National Library of Medicine celebrated its 125th anniversary in 1961 .

Among the speakers at the dedication ceremonies, held December 14-15, 1961, were Senator Lister Hill of Alabama, co-author with the then Senator John F. Kennedy of the National Library of Medicine Act of 1956, which authorized construction of the new building, and Abraham Ribicoff, Secretary of Health, Education, and Welfare.

A gift to the library, presented by Alexis L. Liatis, Ambassador of the Government of Greece, was a cutting from an Oriental plane tree on the island of Cos under which Hippocrates is reported to have taught his pupils. The tree will be planted on the library's 11-acre grounds this spring. 